\title{
A comparison of modern pollen rain collected by Hirst type and Tauber traps in Moscow, Russia
}

\author{
Olga Volkova, Elena Severova \\ Higher Plants Department, Moscow State University, Leninskie Gory, 1, 12, 119234, Moscow, Russia. \\ corresponding author Olga Volkova: \\ e-mail: olgavolkova-msu@yandex.ru
}

Received: 22 April 2017/Accepted: 02 June 2017

\begin{abstract}
The present study compares the pollen spectra from the Hirst type pollen trap and nearby located Tauber traps installed in different vegetations in order to gain knowledge on the pollen vegetation relationship and to assess whether the deposited pollen is in accordance with airborne pollen concentrations. The modern pollen spectra have been monitored over 2016 year in Moscow Region, Russia. Four Tauber traps were installed in different vegetation types: in birch and mixed forests, in the semi-open area (spruce forest) and in open area on peat bog. A comparison between pollen percentages retrieved from Tauber and Hirst type pollen trap shows mostly similar pollen spectra. The spectra from both traps are mostly similar in regard to major taxa. Betula, Pinus and Alnus predominate in the spectra of both traps. The Tauber spectra are characterized by higher taxonomic variability due to greater occurrence of local herbaceous plants. The spectra from Tauber and Hirst type traps represent both local and regional vegetation well.
\end{abstract}

Keywords: pollen deposition, airborne pollen, Tauber trap, Hirst type trap, correlation

\section{Introduction}

Pollen analysis is widely used to reconstruct associations with surrounding vegetation. Hirst type pollen traps are widely used for studying airborne pollen. Efficiency of sampling by that trap is reported to be very high, but is affected by particle size and wind velocity (Levetin et al. 2000; Ranta et al. 2008). Tauber traps are typically used to investigate pollen deposition patterns. The Tauber traps rely on gravity, thus the deposition into this trap types may not reflect true atmospheric composition but be biased toward the larger and heavier pollen types (Levetin et al. 2000, Volkova et al. 2016). Faegri \& Iversen (1989) maintain that the deposition in the traps was only effective in the absence of wind and thus is not "natural" deposition. These findings raise questions about how well pollen spectra from both traps reflect vegetation, whether the pollen of different plants becomes effectively released into the atmosphere, or whether it is predominantly deposited near the source. The simultaneous use of volumetric and gravi- metric samplers can be very useful for palaeoecological studies.

\section{Study area and methods}

The modern pollen spectra has been monitored over 2016 year by using four modified Tauber pollen traps and Hirst type trap situated in the surroundings of the Zvenigorod Biological Station of the Moscow State University in the Moscow Region, Russia. The dominant vegetation types in surroundings of the Station are secondary Picea, Pinus $-P i$ cea and Picea-Betula forests.

Four Tauber traps were located in birch and mixed forests, in semi-open area (spruce forest) and in open area on peat bog. The modified Tauber traps were installed and treated according to Pollen Monitoring Programme (PMP) guidelines (Hicks et al. 1996). Lycopodium tablets were added for calculation of pollen accumulation rate (PAR) (Stockmarr 1971). 
The Hirst type trap (Hirst 1952) was installed on an open rooftop, at $10 \mathrm{~m}$ above ground level in the campus of Zvenigorod Biological Station. The technique of volumetric sampling is a standard procedure used throughout Europe (Galan et al. 2014). Daily airborne pollen observations were performed throughout the period mid-March through mid-October.

\section{Results}

The total annual pollen influx from the Tauber trap was the highest in open site (80277.8 pollen grains $/ \mathrm{cm}^{2}, \mathrm{pg} /$ $\left.\mathrm{cm}^{2}\right)$, and significantly less in semi-open site $\left(525 \mathrm{pg} / \mathrm{cm}^{2}\right)$, in mixed forest $\left(553 \mathrm{pg} / \mathrm{cm}^{2}\right)$ and in birch forest $(467 \mathrm{pg} /$ $\mathrm{cm}^{2}$ ). The cumulative annual pollen levels from the Hirst type trap was $71078 \mathrm{pg} / \mathrm{cm}^{3}$. Twenty pollen taxa were registered in both Hirst and Tauber pollen spectra. Three pollen types were registered by the Tauber traps and represent entomophiflous herbaceous taxa of local vegetation. Six pollen types only registered by Hirst trap were entomophiluous (Rosaceae, Asteraceae, Rubiaceae) and anemophilous (Carpinus, Typha) taxa occurring in local vegetation.

The most abundant arboreal pollen types registered in both samplers were Betula, Pinus and Alnus (Fig. 1). Pollen of Betula accounted for $59 \%, 68 \%, 71 \%$ and $85 \%$ of the Tauber influx in open site, semi-open site, mixed forest and birch forest respectively. The Hirst type sampler registered $44 \%$ of the yearly total for Betula pollen. The total arboreal taxa were higher in the Tauber trap spectra than in the Hirst type trap spectra. In the Tauber trap, the total percentage of arboreal taxa was $91.7 \%, 86.8 \%, 91.1 \%$ and $96.9 \%$ in open site, semi-open site, mixed forest and birch forest respectively. Among herbaceous taxa, Urtica has greater percentage occurrence in the Hirst type trap $(38 \%)$ than in Tauber traps. The highest Urtica pollen occurrence was observed in semi-open site $(2.5 \%)$, whereas in open site $(1.1 \%)$, mixed forest $(0.6 \%)$ and birch forest Urtica was registered in lower percentages. A higher taxonomical diversity was observed in the Tauber traps, twenty pollen types did not reach $1 \%$ of the total pollen count. In the Hirst type trap, seventeen pollen types accounted less than $1 \%$.

\section{Discussion}

A comparison between data retrieved from Tauber traps and Hirst type traps shows similar pollen composition. Among arboreal pollen types, Betula, Pinus and Alnus predominate in the spectra of both traps. Betula and Pinus pollen are part of both regional and local rain (Hicks et al.

\section{open site}

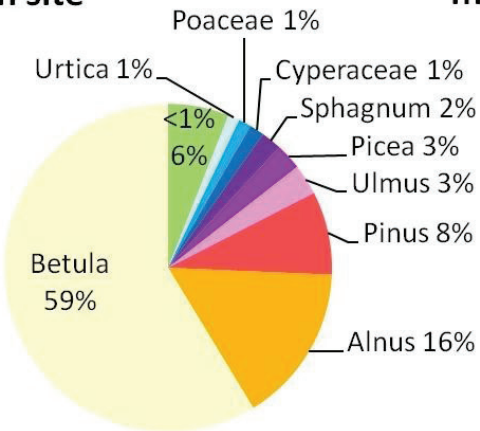

semi-open site mixed forest

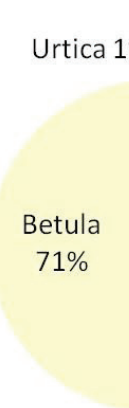

Poaceae $1 \%$
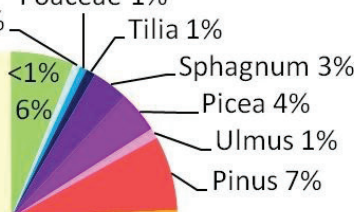

Alnus 5\%

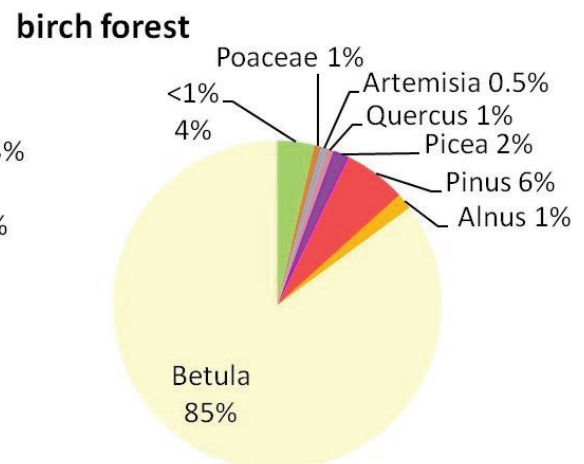

Hirst type trap

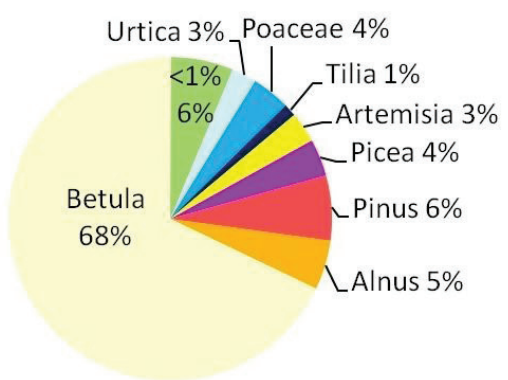

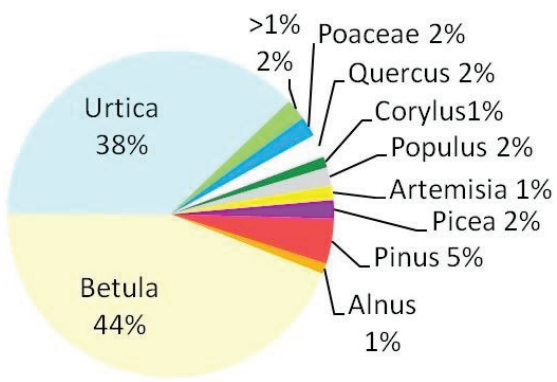

Figure 1. Diagram of pollen concentration values from the Tauber traps installed in different vegetations and from Hirst type trap 
2001; Ranta et al. 2008). These taxa are typical for vegetation around the location of the traps as well as widely occur in regional vegetation. Alnus is not typical for the vegetation around the both traps. Thus, it represents regional vegetation composition. A higher percentage occurrence of Urtica pollen in the Hirst type trap is associated with its abundance in vegetation surrounding the trap. Whereas it is rarely found in vegetation around Tauber traps. The highest Urtica occurrence was observed in Tauber trap located in semi-open site. This trap located near the Hirst type trap where Urtica is widespread in the surrounding vegetation. A higher taxonomical diversity in the Tauber traps is due to its location at ground level, causing capture of pollen originated from local sources and not rising high in the air (Volkova et al. 2016).

Pollen spectra from both traps are mostly similar in regard to major taxa and represent both local and regional vegetation well. The Tauber spectra are characterized by higher taxonomic variability due to greater occurrence of local herbaceous plants. The spectrum from the Tauber traps better reflects local vegetation.

\section{Acknowledgements}

This work was supported by the Russian Science Foundation (RNF), Grant № 14-50-00029 "Scientific basis of the national biobank - depository of the living systems" (branch "Plants").

\section{References}

Fægri K. \& Iversen J., 1989, Textbook of pollen analysis. Chichester, New York, Brisbane, Toronto, Singapore, John Wiley \& Sons.

Galan C., Smith M., Thibaudon M., Frenguelli G., Oteros J., Gehrig R., Berger U., Clot B, Brandao R. \& EAS QC Working Group, 2014, Pollen monitoring: Minimum requirements and reproducibility of analysis, Aerobiologia 30: 385-395.

Hicks S., Ammann B., Latalowa M., Pardoe H., \& Tinsley H., 1996, European Pollen Monitoring Programme: Project description and guidelines, Oulu University Press. Oulu, Finland.

Hicks S., Huusko A., Jensen C., Hatterstrand M., Gerasimides A. \& Kvavadze E., 2001, Some comments on spatial variations in arboreal pollen deposition: First records from the Pollen Monitoring Programme (PMP), Review Palaeobotany Palynology 117: 183-194.

Hirst J., 1952, An automatic volumetric spore trap, Annals of Applied Biology 39: 257-265.

Levetin E., Rogers C.A. \& Hall S.A., 2000, Comparison of pollen sampling with a Burkard spore trap and a Tauber trap in a warm temperate climate, Grana 39: 294-302.

Ranta H., Sokol C., Hicks S., Heino S. \& Kubin E., 2008, How do airborne and deposition pollen samplers reflect the atmospheric dispersal of different pollen types? An example from northern Finland, Grana 47: 285-296.

Volkova O., Severova E. \& Nosova M., 2016, Six years of observation of airborne and deposited pollen in central European Russia: first results, Grana 55: 311-318.

Stockmarr J., 1971, Tablets with spores used in absolute pollen analysis, Pollen et Spores 13: 615-621. 